\title{
The acquisition of sociolinguistic evaluations among Polish-born adolescents learning English: evidence from perception
}

\author{
Lynn Clark $^{1} \&$ Erik Schleef ${ }^{2}$ \\ ${ }^{1}$ Lancaster University, UK \\ ${ }^{2}$ University of Manchester, $U K$ \\ ${ }^{1}$ Linguistics and English Language \\ Lancaster University, \\ Lancaster, LA1 4YD, UK \\ ${ }^{2}$ Linguistics and English Language \\ University of Manchester, \\ Manchester, M13 9PL, UK
}

(Received 13th April 2010, revised 2nd July 2010)

\begin{abstract}
In order to achieve full native-like competence in a second language, speakers must also acquire sociolinguistic awareness in that language. This article reports the results of a study investigating the acquisition of sociolinguistic awareness among immigrant Polish adolescents learning English in the UK. This paper asks whether Polish-born adolescents living in the UK can identify different varieties of British English as well as their nativespeaker peer group can, and whether they share similar evaluations of these varieties of English as their native-speaker peer group. The results of a variety recognition survey suggest that Polish-born adolescents now living in the UK are not yet able to identify different varieties of English. However, the vast majority of evaluations carried out by Polish-born adolescents and UK-born adolescents were not statistically different. Furthermore, we see clear evidence of the acquisition of the muted evaluations typically associated with the two varieties of English that are most positively and negatively evaluated among the UK-born adolescents: RP and Birmingham English. We suggest that our study provides a snap-shot of the initial stages of the acquisition of attitudes towards variation in a second language.
\end{abstract}

Keywords: immigration, acquisition, sociolinguistic awareness; Polish

\section{Introduction}

It has become clear through decades of research in the sociolinguistics paradigm that speakers of any language know about variation in their native language. Work within the Labovian tradition of sociolinguistics (see, for instance, Labov 1969, 1972, 2001) has shown that speakers are typically quite consistent in the patterns of variability that they display across a community. There is also a significant body of research, beginning with Giles and Powesland's (1975) seminal work, which suggests that 
speakers are relatively consistent in the social judgements that they attach to variation in their native language variety. This makes the task of fully acquiring a second language especially difficult because it requires more than simply learning the rules of the L2 grammar; in order to achieve full native-like competence in a second language, speakers must also acquire the following:

- Similar frequencies of variation as found in the target language community

- Similar social and linguistic constraints on variation as found in the target language community

- Similar social judgements on variation as found in the target language community.

In other words, achieving full native-like competence in a second language also requires the successful acquisition of sociolinguistic knowledge of that language (or variety). This article reports the results of a study investigating the acquisition of sociolinguistic awareness among immigrant Polish-born adolescents learning English in the UK.

The number of Polish immigrants now living in the UK has increased dramatically since Poland became a member of the EU in 2004. The UK was one of only three countries (with Ireland and Sweden) to allow Eastern European workers virtually unrestricted access to its labour markets and this has resulted in the "largest single wave of in-migration that the British Isles have ever experienced" (Salt and Millar 2006: 335). It is difficult to find accurate estimates for the number of Polish immigrants now living in the UK but data from the Workers Registration Scheme (Bauere et al. 2007) suggests that recent immigrant workers from Poland are settling in communities throughout the British Isles ${ }^{1}$.

The Polish migrant workforce is a population of young adults, many of whom also have children living with them in the UK. A study of adolescent Polish immigrants provides an interesting viewing platform for linguistic contact situations because adolescents are of an age at which they are especially adaptable, they are in 
constant contact with a peer group of L1 English speakers and they can be easily accessed through schools, which are themselves "microcosms of society, representing and often magnifying social relations that exist in the wider community" (Reynolds 2008:9). Our project therefore focuses exclusively on the linguistic attitudes and behaviour of the adolescent generation of recent Polish immigrants to the UK.

Schleef et al (under review) report previous findings from this project which discuss Polish-born adolescents' use of variation in the English (ing) variable (with variation between [In] and [Iy] in words of two or more syllables ending in ing). Schleef at el (under review) suggest that while Polish-born adolescents are adopting relatively similar frequencies of variation in (ing) as their native-speaker peer group, they are not adopting the same underlying constraints on this variation as displayed by their native-speaker peer group ${ }^{2}$. Rather, Polish-born adolescents are reinterpreting the constraints which operate on variation among native speakers in a process Meyerhoff (2003) calls 'transformation under transfer'. Our research on variation in the production of English (ing) adds weight to the proposition that transformation under transfer is a fairly general principal, operating in a number of different types of language contact situations.

This current article builds on the discussion of the acquisition of sociolinguistic awareness in English among Polish-born adolescents in Schleef et al (under review) by focussing on the perception end of sociolinguistic competence. Specifically, this paper asks whether Polish-born adolescents living in the UK can identify different varieties of British English as well as their native-speaker peer group and whether they share similar evaluations of these varieties of English as their native-speaker peer group. We begin by contextualising our research against previous work on the role of attitudes towards varieties of English. 


\section{Attitudes towards variation in English}

The first studies to attempt to empirically measure speakers' attitudes towards languages and language varieties were conducted by social psychologists. The motivating assumption was the notion that speakers hold certain attitudes about the social value of linguistic variation and linguistic practices and that "attitudes towards a particular way of speaking...in reality are evaluative reactions towards people who speak that way" (Kristiansen \& Monka 2006: 2). Since Lambert et al. (1960) first applied the Matched Guise Technique to an investigation of the attitudes held towards French and English among Francophone and Anglophone Canadians, there has been a plethora of language attitude research employing similar methodologies across a number of different language situations. This research also paved the way for studies investigating the social judgments that speakers hold towards accent variation in their native language, the first of which (Tucker \& Lambert 1969) explored attitudes towards regional and ethnic varieties of English in the USA. Two main generalisations have emerged from this long line of research:

1) Speakers/judges typically evaluate standard varieties of their native language highly in terms of prestige and status but lower in terms of solidarity (i.e. speakers of a standard variety are likely to be regarded as sounding educated, intelligent and confident but are less likely to be regarded as sounding funny, likeable or trustworthy).

2) Speakers/judges often evaluate non-standard varieties of their native language highly in terms of solidarity but lower in terms of prestige and status (i.e. speakers of a non-standard variety are likely to be regarded as sounding funny, likeable or trustworthy but are less likely to be regarded as sounding educated, intelligent or confident).

Within a British context, the largest and most recent study to investigate the attitudes that native speakers of English hold towards varieties of English comes from Coupland \& Bishop (2007). This study attempted to capture subjective evaluations of 34 accent varieties of English with large-scale survey methodology. Using material from the BBC Voices project (http://www.bbc.co.uk/voices/), 5010 speakers 
of English living in the UK were asked to produce scaled responses to a list of 34 variety labels often applied to English in the UK. The judges were asked to rate each variety label on a scale of 1-7 with respect to the prestige and pleasantness that they associate with each variety, therefore effectively assigning an empirical value to their own linguistic stereotypes. The results of this large-scale study confirm the results of previous smaller studies (e.g. Giles 1970). Some of the overall tendencies are that:

- Birmingham English is the 'bête noire of British accents' (Bishop et al 2005: 1 ); it is consistently rated as one of the least prestigious and least socially attractive varieties of English

- RP (described in this study as 'Queen's English') is consistently regarded as one of the most prestigious varieties of English, although it is not considered the most socially attractive variety

- The non-standard varieties Newcastle English, Southern Irish English and Afro Caribbean English are rated far higher in terms of social attractiveness than prestige

- Edinburgh English is one of the most favoured accents on both dimensions; Scottish English is also highly favoured for prestige and social attractiveness. A number of social factors were found to be significant predictors of variation in responses among the 5010 judges. For instance, among the Scottish respondents there is evidence of in-group loyalty: the Scottish respondents who took part in the survey provide more positive judgements towards the labels Edinburgh English, Glasgow English and Scottish English than respondents from other regions of the UK. Also, respondents from the south east of England report significantly higher ratings of social attractiveness for the labels 'Queen's English' than respondents from other areas of the country; Northern Irish, Scottish and Welsh respondents produce the lowest ratings of Queen's English. There is also evidence of a significant gender effect: "There is a reliable tendency for women to afford a given accent more prestige" (Coupland \& Bishop 2007: 80). The age of the respondent is an important predictor of variation on response ratings although it is difficult to generalise this result because significant differences with age are not always linear. The responses to the variety label 'Standard English', however, do pattern linearly with age: the older 
informants attribute this variety label with more prestige than the younger informants in the study (although it is still rated positively among younger informants).

Despite some significant differences in the evaluation of certain varieties of English by the age and sex of the respondent and by the area of the country in which they live, this study is the largest and most recent in a long line of studies on attitudes towards accents of English to show that, overall, the British population share overwhelmingly similar views regarding the prestige and social attractiveness of certain varieties of English in the UK (and that these views have changed very little over time; see Bishop et al. 2005 for further discussion of this point). Our research questions the extent to which immigrant communities learning English in the UK adopt similar linguistic stereotypes to those that have become so entrenched in the minds of the British population.

Research on language attitudes is of "major importance" in work on second language acquisition (Ellis 1994: 197). This is because positive learner attitudes towards the target language, its speakers and its culture have all been found to enhance second language acquisition, predisposing learners to making more effort to learn the L2 (see Gardner 1985 for work on attitudes in second language research; see Dörnyei et al. 2003, Dörnyei 2003 for an overview of research on motivation in second language acquisition). And yet despite the importance of attitude research in studies of second language acquisition, there is very little research dealing explicitly with attitudes towards variation in the L2. Rather, as McKenzie (2008a: 66) points out, the vast majority of studies which have investigated non-native speaker attitudes have tended to measure evaluations towards 'English' as a single monolithic construct. Of course, some studies exist which do attempt to measure non-native speakers' perceptions of varieties of English. We briefly review some of these here 
before moving on to discuss results from our own research on the attitudes displayed by Polish immigrants towards variation in English.

Of the few studies which do examine learner attitudes towards variation in English, typically the focus is on examining the attitudes of learners of English in countries where English is not the L1. One of the largest empirical approaches to this research question is McKenzie (2010). Using the Verbal Guise Technique ${ }^{3 \text {, }}$ McKenzie (2010) investigated evaluative judgements of 558 Japanese university students (in Japan) towards six varieties of English (Glasgow vernacular, Glasgow Standard, Southern US English, Midwest US English, moderately accented Japanese, heavily accented Japanese). Within a European context, and also using the VGT, Ladegaard (1998) asked 96 Danish secondary school and university students of English to evaluate 5 varieties of English (Cockney, Australian, Scottish, RP and General American) along dimensions of status and solidarity; Jarvella et al. (2001) conducted a similar study using only non-standard varieties of English as accent stimuli for advanced Danish learners of English; Dalton-Puffer et al. (1997), also using the verbal guise technique, elicited subjective evaluations from 132 Austrian university students of English towards five varieties of English (RP, 'near' RP, General American and two 'weak but recogniseable' Austrian accents of English). Within the European context at least, these studies cited above tend to report similar results to those from studies of L1 users of English i.e. RP is generally regarded highly in terms of status and prestige whereas non-standard varieties are often evaluated more highly in terms of solidarity and social attractiveness. McKenzie (2008a) suggests that the high status evaluations of RP are probably due to learners' familiarity with that variety as a model for learning English in Europe. The responses to non-standard dialects could simply be reactions to stimuli that sound different from 
the standard variety. In other words, it is unclear from these studies whether foreign language learners of English are adopting the same evaluative judgements towards varieties of English as L1 speakers or whether they are simply reacting to standard and non-standard accents and applying the mantra that more standard-like accents are rated as prestigious and less standard-like accents are rated as socially attractive. We know from previous work (e.g. see Coupland \& Bishop 2007, above) that L1 speakers of English in the UK do not evaluate all non-standard accents in the same way and so comparing L2 speaker results with evaluative judgements from a socially matched group of L1 learners could help us to reach a better understanding of this process.

One study to have taken this approach is an early example of language attitude research among non-native speakers of English. Eisenstein (1982) explored the developing attitudes of immigrant adult learners of English in NYC towards five different varieties of English. The varieties of English were chosen such that the learners would have undoubtedly been exposed to three of them previously (Standard English/General American, New Yorkese and Black English) but two others were unfamiliar accents (Irish-accented English and Hawaiin pidgin English). This study found a significant correlation between level of proficiency in English and similarity to native-like evaluations of these five varieties of English: advanced learners of English appeared more native-like in their ability to differentiate between these varieties and to socially evaluate them. Specifically, the more advanced learners provided more extreme negative evaluations towards the non-standard accents. This suggests that learners acquire linguistic stereotypes about English at much the same rate as they acquire English. Eisenstein's early study is still one of the only studies to examine the acquisition of attitudes towards variation in English among learners living in the host community. Eisenstein's research focussed on adult immigrants but 
we should bear it in mind as we turn now to an exploration of the language attitudes displayed among adolescent Polish immigrants learning English and living in the UK. Specifically, this article considers (a) whether Polish adolescent immigrants can accurately identify different varieties of English and (b) whether Polish adolescent immigrants are adopting the same evaluative judgements towards varieties of English as their locally-born peer group.

\section{Methods}

The data for this project were collected from immigrant Polish communities living in two major cities in the UK - Edinburgh and London. Our study was conducted in two high schools, one in Edinburgh and one in London, where recent immigration has led to an increase in the number of non-locally born students. We collected data from Polish migrants and teenagers from local British families so as to have a benchmark of the local norms that the teenage migrants were exposed to most frequently. Students volunteered for the study following a presentation from the research assistant about the general nature of the tasks. The data were collected in friendship pairs in order to facilitate the most casual atmosphere possible given the school-based setting for the data collection (Milroy and Gordon 2003: 66).

The Edinburgh sample consisted of 16 Polish migrants ( 8 males, 8 females) and 21 Edinburgh-born teenagers. The London sample consisted of 21 Polish migrants ( 8 males, 13 females) and 24 London-born teenagers. The Polish teenagers were all aged between 12-18 with a mean age of 14 in both the London and Edinburgh samples. The length of time that each adolescent had spent in the UK varied from seven months to 5 years, with an average in both cities of 2.5 years in the UK. 
Following previous research on attitudes towards varieties of English among non-native speakers, the primary tool used to elicit subjective reactions towards different varieties of English was the Verbal Guise Technique (hereafter VGT; Ladegaard 1998). Arguably, the Matched Guise Technique (MGT) is a more scientifically robust tool because the MGT attempts to reduce the number of potentially confounding variables. By using the same speaker to produce multiple guises, it is largely possible to control for differences in pitch, speech rate and voice quality. However, the MGT is most successful when it is employed in studies which explore subjective reactions to only two language varieties. It is relatively straightforward to find convincing bilingual or bi-dialectal speakers who are willing to perform two guises. This becomes increasingly difficult as more guises are included in the research design. In this case, it would have been virtually impossible to find a single speaker to authentically reproduce all 8 guises in this experiment. Hence, for practical reasons, the VGT was implemented here.

Eight university-educated females of similar age and social background were recorded reading a short text about an animal rescue operation that was taken from Newsround (http://news.bbc.co.uk/cbbcnews/hi/uk/default.stm), a television news programme and website aimed at children and teenagers. Newsround provided us with a neutral text that was written using language familiar to our target age group. Efforts were made to match the guise recordings for voice quality and speech rate (cf. Ladegaard 1998). The guises in this study represent the following accents of English:

- Edinburgh English

- London English

- Received Pronunciation (RP)

- Scottish Standard English (SSE)

- Manchester English

- Birmingham English 
- Newcastle English

- Polish English

Edinburgh English and London English were included as the two local varieties which Polish immigrants living in these two communities are regularly in contact with (and so are the most likely to be correctly identified). RP and SSE were included because these are the two prestige varieties of English in Scotland and England. Birmingham English, Manchester English and Newcastle English were included because these urban varieties of English evoked a range of different responses from British respondents in Coupland \& Bishop (2007). Birmingham English is typically the most negatively evaluated of all accents of English in the UK, Newcastle English is much more highly regarded in terms of social attractiveness than prestige or status and Manchester English sits just below mid way in the list of 34 accents in Coupland \& Bishop (2007); that is, Manchester English does not evoke especially positive or negative reactions on either status/prestige or social attractiveness. Finally, Polish English was included in order to elicit attitude responses towards something approximating the Polish-born adolescents' own variety of English because in Coupland \& Bishop (2007), judges tended to positively evaluate their own accent, both in terms of status and social attractiveness.

Subjective evaluations of these eight varieties of English were captured in two ways. Following previous research in the VGT paradigm, the adolescents' reactions to these 8 guises were elicited indirectly using a semantic differential scale. AlHindawe (2006) suggests that the adjectives used in semantic differential scales should reflect the adjectives actually used by speakers in the speech community i.e. researchers should not simply assume that the same traits will necessarily be salient for different groups of speakers. In an effort to include adjectives which were likely 
to be meaningful to the judges in this study, undergraduates from Edinburgh and London attending the University of Edinburgh were asked to describe these guises in their own words. The ten most frequently occurring adjectives (and their antonyms) were selected for inclusion in the semantic differential scale. The adjectives were then randomised in order to avoid any left-right bias (cf. McKenzie 2007: 59). The semantic differential scale used in this study is provided below in Figure 1 (along with instructions for the judges).

\section{[INSERT FIGURE 1 HERE]}

In friendship pairs, the adolescent judges were exposed to each guise twice played through a set of Sony speakers connected to a laptop. They were then asked to evaluate each guise in terms of these ten adjectives by placing a cross somewhere along the dashed line. The cross should represent the strength of agreement with each trait. The dashed line consists of 100 dashes and so it is relatively simple to assign a value ranging from 1-100 to the cross on each line. This method draws on the principles of magnitude estimation (cf. Bard et al. 1996) and allows for a more finegrained analysis of the data than techniques which employ a traditional five or sevenpoint Likert scale (Bard et al. 1996: 35$)^{4}$.

This indirect approach to eliciting subjective reactions was followed by two summary questions ('would you vote for this person if she was a politician?' and 'would you like to have this person as a friend?'). These questions attempted to elicit a more direct response to the status and solidarity dimension of each guise. Finally, following McKenzie's (2008b) work on variety recognition, the adolescents in this study were also asked if they could identify where they though the voice they were hearing came from and how they though they know this. This was done directly after 
listening to the guise with the use of a questionnaire, however the fieldworker was still present in case the adolescent judges were in need of further clarification.

\section{Results}

\section{Variety recognition}

The first stage of the analysis was to ascertain the accuracy with which Polish adolescent immigrants living in Edinburgh and London could identify the eight different varieties of English presented in the VGT. This was not a straightforward task. Because the adolescents were not provided with a forced-choice questionnaire, it was often difficult to conclude whether a given response was indeed correct. The adolescents in this study were asked to be as specific as possible in their responses but in some cases they were unable to narrow the region down any further than a general notion that the speaker was 'British' or 'from the UK'. Technically, a response which categorises the Edinburgh guise, for instance, as being from the UK is not incorrect. However, it is not as accurate as it could be. McKenzie (2008b) faced a similar problem, also caused by the use of an open-ended variety recognition question rather than a forced-choice questionnaire. The informants in McKenzie's (2008b) study were Japanese learners of English living in Japan and so McKenzie chose not to impose unrealistically narrow expectations. He interprets his respondents' answers as liberally as possible and would accept a response which categorised an Edinburgh guise as 'British' as correct. However, the informants in the present study are all living in the UK and so perhaps it is reasonable to expect them to be more aware of regional variation in UK English. Given that some of our guises can be localised more narrowly than others, we adopted a differential scoring system. 
In the case of the Polish English guise, this was ultimately unnecessary as the responses to this guise were either 'Poland' or somewhere else entirely (e.g. Africa). In other words, responses to the Polish English guise were unequivocally correct or incorrect. Correct identification of the Polish English guise was therefore measured on a binary scale ( 0 or 1$)$. However, the two standard varieties are more complicated because it is possible to narrow down the place of origin to some extent: SSE speakers are very likely to come from Scotland and RP speakers are much more likely to come from the south east of England than anywhere else in the UK. In this case, a reference to the speaker being from somewhere in the UK was given 1 point but a more localised identification of Scotland or England was given an extra point. This means that the correct identification of the two standard varieties was measured on a scale from 0-2. Finally, the responses to the guises which could be localised to a particular city were given an extra point if the city was given correctly. This means that correct identification of the five urban varieties were measured on a scale of 0-3. Table 1 further illustrates the methods used to quantify correct identification in this study.

\section{[INSERT TABLE 1 HERE]}

Table 2 presents the mean identification results for each guise and all four groups of judges.

\section{[INSERT TABLE 2 HERE]}

The recognition rates for the Polish English guise are generally very high among all 4 groups but the Polish-born adolescents are consistently more accurate at identifying the Polish English guise than their native-speaker peer group (although this difference only reaches significance among the two groups of London adolescents ( $\mathrm{t}$ test: $\mathrm{p}=0.003$ ); in Edinburgh, the higher accuracy rates among Polish-born 
adolescents is only a tendency. This result parallels McKenzie's (2008b) finding that among Japanese learners of English, the most accurately identified variety of English was Heavily-accented Japanese. This finding simply demonstrates a high degree of familiarity with Polish English among the Polish-born adolescents in this study.

A very different pattern emerges regarding the identification results of the two standard guises. Polish-born adolescents living in London and Edinburgh are significantly worse at correctly identifying the regional origin of SSE or RP than their native-speaker peer group. Polish-born adolescents living in London were especially puzzled by the SSE guise (less than 5\% accuracy in responses). Examining the incorrect responses offered in this case sheds no further light on the matter. Two of the incorrect responses suggested that the speaker may be from Ireland and so it is tempting to suggest that the judges were responding to something in the phonology of this guise (e.g. rhoticity). Other incorrect responses include suggestions that the SSE guise is from Russia, Asia, India, Italy, Czechoslovakia, Germany, France and Spain. Although these responses seem random and could simply indicate lack of experience with the variety (Williams et al. 1999), it is interesting to note that a number of these languages also have post-vocalic $/ \mathrm{r}^{15}$.

Identification values for the five urban varieties are low for all groups in table 2. This time, the native-speaker adolescents have difficulty correctly identifying the city of origin for the five urban varieties. This is unsurprising. We know from previous research on dialect recognition studies among native adolescents that even in a forced choice task, naive adolescent listeners are typically only able to correctly identify the specific origin of a speaker around $30 \%$ of the time (e.g. Williams, et al. 1999). The identification scores among the Polish-born adolescents are in all cases significantly lower than their native-speaker peer group. Interestingly, 
the Polish-born adolescents living in Edinburgh are better at identifying the Edinburgh guise than the four other urban varieties and, similarly, the Polish-born adolescents living in London are better at identifying the London guise than the other four urban varieties. Again this is to be expected: although the overall rate of correct identification in Williams et al. (1999) was 30\%, listeners were far more accurate at categorising speakers from their own region (45\%) compared with other regions $(25 \%)$.

To summarise, the Polish adolescent immigrants in this study are better than their native-speaker peer group at identifying Polish English but significantly worse than their native-speaker peer group at identifying other standard and non-standard varieties of British English. What are the consequences of this result? Given that “...one would expect that low levels of dialect recognition would necessarily limit people's ability to position themselves psychologically within, or in opposition to, local community norms" (Williams et al. 1999: 345), it is reasonable to expect that speakers who cannot accurately identify the localized variety of a particular guise will therefore not be able to access any predetermined linguistic stereotypes surrounding these varieties. We might therefore predict that Polish-born adolescents living in the UK will evaluate these guises differently as a result. This is discussed in the following section.

\section{Evaluative judgments}

The first step in the analysis of the evaluative judgements assigned during the verbal guise experiment was to compare overall mean evaluations for each guise across all four groups of judges (Edinburgh-born adolescents, Edinburgh-based Poles, London-born adolescents, London-based Poles). Responses were extracted from the 
semantic differential scale and, where necessary, transposed in order that a positive evaluation was always represented with a higher value. The range of possible evaluations spans 1-100 and the most positively evaluated guises are presented here with a value closer to 100 . The overall mean evaluations of each guise by all four groups of judges are presented in figure 2:

\section{[INSERT FIGURE 2 HERE]}

There is virtually no difference in mean evaluations of the eight guises between the four groups of judges. Evaluations of the RP guise are the only mean evaluations which are significantly different (London-born adolescents evaluate this variety higher than all other groups ( $\mathrm{t}$ test: $\mathrm{p}=0.000)$ ). However, these are mean scores which could be hiding differences in the reactions to each guise on specific personality traits.

In order to consider this point, it is necessary to examine the evaluative judgements of UK-born adolescent judges before we compare the behaviour of the Polish-born adolescents. Figures $3 \mathrm{a}$ and $3 \mathrm{~b}$ display the mean personality trait evaluations for Edinburgh-born and London-born adolescents. As before, the y-axis ranges from 1-100 and represents the range found on the semantic differential scale. The $\mathrm{x}$-axis presents results from the ten personality traits that the judges were asked to respond to. These personality trait adjectives have been grouped into three underlying traits or supervariables labelled 'status/power', 'social attractiveness' and 'solidarity'. These underlying evaluative dimensions were arrived at after the data were subjected to the data reduction technique of principal components analysis (PCA). PCA allows the researcher to examine the underlying structure of the data, and to identify relationships between the adjectives in the semantic differential scale. PCA is typically applied to larger data sets than this and so although the underlying traits 
were found to pattern in a statistically significant way, the lack of data in this case suggests that these underlying traits or supervariables should be viewed as patterns or tendencies, rather than absolutes (see McKenzie 2010 for further discussion of the merits of PCA).

\section{[INSERT FIGURE 3A]}

\section{[INSERT FIGURE 3B]}

For both the Edinburgh-born and London-born adolescents, the PCA revealed three components with eigenvalues over $1.0^{6}$. The underlying components extracted (represented as supervariables on the $\mathrm{x}$-axis of figures $3 \mathrm{a}$ and $3 \mathrm{~b}$ above) are very similar for both the Edinburgh and London-born adolescents. The only difference is that among the Edinburgh-born adolescents, the personality trait 'educated' patterns with other 'status' traits but in the London data it patterns with 'social attractiveness' adjectives.

Not only are the supervariables similar between these two data sets; the evaluative judgements towards the eight guises are also similar between adolescents in Edinburgh and London. In both data sets, the social attractiveness traits cluster together around the middle of the range suggesting that on this dimension, neither the adolescents from Edinburgh nor London hold any strong feelings towards the guises presented here. However, there is a much greater range of evaluations on the status/power and the solidarity dimensions. This is because the RP and Birmingham English guises elicit some extreme reactions from these adolescents (highlighted in bold in figures $3 \mathrm{a}$ and $3 \mathrm{~b}$ ). In the data from the Edinburgh-born adolescents (figure 3a), RP is evaluated especially highly on the status/power dimension but low on the social attractiveness and solidarity dimensions. Birmingham English is rated low on all three dimensions but this is especially the case in the solidarity dimension. In the 
data from the London-born adolescents (figure 3b), RP is evaluated particularly highly on the status/power and social attractiveness dimensions but low on the solidarity dimension. Birmingham English is rated low on all three dimensions and, again, this is especially true in the solidarity dimension. These data suggest that, with respect to the RP and Birmingham English guises, the Edinburgh-born and Londonborn adolescents behave in a similar way to adults from previous studies (Coupland \& Bishop 2007). That is, RP is recognised as a high status variety and Birmingham English is recognised as the 'bête noire of British accents' (Bishop et al 2005: 1). However, evaluations of the other six guises seem to be less extreme and less developed, with mean values occupying the middle of the range. To what extent are these evaluative judgement patterns replicated by Polish-born adolescents living in Edinburgh and London?

The Polish-born adolescents' evaluative judgements of these eight guises are reported in figures $4 \mathrm{a}$ and $4 \mathrm{~b}$.

\section{[INSERT FIGURE 4A]}

\section{[INSERT FIGURE 4B]}

First, the underlying evaluative dimensions (or supervariables) in these data are quite different from those found among the native-speaker judges. In the data from the Edinburgh-based Poles (figure 4a), only two underlying traits were extracted from the PCA. The solidarity traits cluster together in a similar way as for native-speaker judges in Edinburgh but the remaining seven traits do not. In the data from the London-based Poles (figure 4b), three underlying traits were extracted from the PCA but these pattern a little differently from the three underlying traits extracted from the London-born adolescents' data. For the London-born adolescents, the adjective 'rich' patterns with the status/power adjectives (as expected) but for the Polish-born 
adolescents living in London, the adjective 'rich' patterns, rather unexpectedly, with the solidarity traits.

Second, the range of evaluative responses for these 8 guises among the Polishborn adolescents is smaller than for the UK-born adolescents; their reactions to the majority of these guises and adjectives sit somewhere around the middle of the range.

Third, reactions to the guises RP and Birmingham English (which represent opposite extremes of status and solidarity for the native adolescents in this study) do not pattern in exactly the same way among Polish-born adolescents living in the UK as they do for UK-born adolescents. However, there are some similarities. The Polish-born adolescents living in Edinburgh (figure 4a) do not evaluate RP as highly in terms of status/power (SSE is more highly regarded among Polish-born adolescents living in Edinburgh), but Birmingham English and RP are both rated among the lowest of all 8 guises on the solidarity dimension. A similar pattern exists in the London data. The Polish-born adolescents living in London do not evaluate RP any more highly than any other variety in terms of status/power but on the solidarity dimension, the pattern is similar to London-born adolescents as Birmingham English is evaluated lower than all other guises. These results suggest that the Polish-born adolescents living in Edinburgh and London are beginning to acquire similar patterns of evaluative judgements as those displayed by their native-speaker peer group. We see this most clearly in (a) the solidarity dimension and (b) the most extremely negatively evaluated variety of British English: Birmingham English. Our interpretation of these findings are considered more thoroughly in the following section.

Once the data from Edinburgh and London were tested for normality (Kolmogorov-Smirnov test) and homogeneity of variance (Levene Statistic), they 
were next subjected to a one-way repeated measures Analysis of Variance (ANOVA) which compared the mean evaluations of each speaker group (i.e. the two groups of judges from Edinburgh were compared against each other and the two groups of judges from London were compared against each other) across each guise and trait and estimated the significance of the difference between them. In total, 80 calculations were produced for each set of comparisons (i.e. eight guises times ten traits in the Edinburgh data and eight guises times ten traits in the London data) but for convenience, only those which showed significant differences are reproduced here. The ANOVA for the Edinburgh data (comparing mean evaluations of Edinburgh-born adolescents and Polish-born adolescents living in Edinburgh) are presented in table 3; results of the London ANOVA (comparing mean evaluations of London-born adolescents and Polish-born adolescents living in London) are presented in table $4^{7}$.

\section{[INSERT TABLE 3]}

The patterns described in figures $2 \mathrm{a}$ and $3 \mathrm{a}$ are broadly confirmed by these ANOVA results from the Edinburgh data. The main area of difference is in the evaluation of the RP guise, especially on the status/power dimension. Edinburghborn adolescents rate the RP guise as significantly higher in status/power than Polishborn adolescents living in Edinburgh. Edinburgh-born adolescents also rate the Birmingham guise as significantly lower on the traits interesting and educated than Polish-born adolescents living in Edinburgh. In other words, although the Polish-born adolescents living in Edinburgh evaluate the Birmingham accent lower than any other in the solidarity dimension, they have not yet acquired the same strength of negative association with this accent as shown by their native-speaker peer group. This is especially apparent with the trait 'interesting' which, for Edinburgh-based Poles, 
achieves a low mean evaluation of 32.4/100 but for Edinburgh-born adolescents achieves a significantly lower mean evaluation of 12.5/100. Finally, Edinburgh-born adolescents rate the SSE speaker significantly higher in reliability than Polish-born adolescents living in Edinburgh.

The pattern described in figures $2 \mathrm{~b}$ and $3 \mathrm{~b}$ for the London data are also confirmed by the ANOVA in table 4 .

\section{[INSERT TABLE 4]}

As in the Edinburgh data, ANOVA results from the London data may reflect the fact that the Polish-born adolescents living in London have not yet acquired the same strength of reaction to RP and Birmingham English, the two varieties of English which occupy opposite ends of the judgements spectrum for adolescents from London. London-born adolescents rate the RP guise significantly higher in status/power than Polish-born adolescents living in London. London-born adolescents also rate the Birmingham guise significantly lower on the traits 'reliable' and 'posh' than Polish-born adolescents living in London. Again, this does not necessarily mean that Polish-born adolescents do not evaluate Birmingham English as a low status variety of English; it seems from the data presented in figure $3 b$ that they do, at least in terms of solidarity traits. For instance, the ANOVA results simply highlight that the strength of reaction shown towards these two varieties of English is much weaker among Polish-born adolescents living in London than it is for Londonborn adolescents.

These ANOVA results point to another interesting pattern which is less apparent in figures $3 \mathrm{~b}$ and $4 \mathrm{~b}$ : London-born adolescents evaluate the Edinburgh guise significantly higher on the traits 'interesting', 'friendly' and 'intelligent' than Polishborn adolescents living in London. The high status afforded the Edinburgh accent by 
London adolescents is in line with the general tendency found among British adults. Coupland \& Bishop (2007) found that the Edinburgh accent is regarded as one of the top 5 British accents in terms of both status and solidarity. These ANOVA results suggest that Polish-born adolescents living in London have not yet acquired this evaluative judgement. Finally, London-born adolescents rate the London guise significantly lower on one trait ('posh') than Polish-born adolescents living in London. Again, however, for both groups of judges the evaluation is negative but the Polish-adolescents' reaction is not as negative as the London-born adolescents' reaction to this guise on this particular trait.

\section{Discussion}

The results of the variety recognition survey (table 2) suggested that Polishborn adolescents living in the UK are not nearly as able to identify different varieties of English as their native-speaker peer group. Of course, this is not a binary phenomena, as the results in table 2 show. This means that Polish-born adolescents presumably cannot access predetermined stereotypes about these varieties because they cannot accurately identify the localized variety. The hypothesis here was that Polish-born adolescents would evaluate varieties of English differently than UK-born adolescents (i.e. they would show no signs of having acquired sociolinguistic awareness in the task of assigning judgement values to varieties of English).

The results in tables 3 and 4 above highlighted some areas of difference in evaluation strategies between the verbal guise data from UK-born and Polish-born adolescents. Statistically, the Polish-born adolescents and British adolescents seem to differ most in their evaluations of those varieties that have been shown to evoke the most extreme reactions among native speakers, i.e. they differ most clearly in their evaluations of RP English and Birmingham English. However, when these statistical 
differences are viewed alongside a more holistic summary of the general patterns in these data (i.e. figures 3 and 4) it becomes apparent that the statistical differences are not always indicative of differences in direction of reaction (i.e. positive or negative) to these guises but rather differences in strength of reaction. The Polish-born adolescents, despite not being able to accurately identify where these guises come from, are beginning to follow the same general tendencies as their native-speaker peer group. One striking pattern is that the Polish-born adolescents from Edinburgh and London rate the Birmingham accent lower on the solidarity dimensions than they do for any other guise.

We suggested in section 1 that the results of previous studies on the attitudes shown by foreign learners of English towards variation in English are difficult to interpret. This is because it is unclear whether foreign judges evaluate the nonstandard varieties negatively because they are acquiring the linguistic stereotypes associated with these varieties or because they are aware that these varieties are nonstandard and so they evaluate them as such. In this case, however, our Polish judges were presented with a number of non-standard accents of English yet in both data sets, the Birmingham guise was consistently rated as the lowest. If the Poles in our study had simply been responding to the fact that the accent sounded somehow nonstandard, there is no reason why the Birmingham accent should have been evaluated any lower than, for instance, the Newcastle accent.

The negative evaluations of the Birmingham accent by Polish-born adolescents in this study can be explained in one of two ways. The first possible explanation is that the Birmingham accent is intrinsically aesthetically inferior and Poles in this study are reacting to something inherent in the accent. This is a suggestion that linguists have been at pains to reject. Edwards (1982:21) suggests that 
there is little or no evidence to support the idea that some varieties of language are more aesthetically pleasing, more logical, more correct or 'better' than others. Giles \& Coupland (1991) conclude from this that "the evaluations of language varieties do not reflect intrinsic linguistic or aesthetic qualities so much as the levels of status and prestige that they are conventionally associated with in particular speech communities" (1991: 37-8).

By rejecting this proposal, only the second explanation is feasible: Polish-born adolescents consistently regard the Birmingham accent lowest in terms of solidarity because they are in the process of acquiring the social stereotypes associated with this variety of English which is perhaps taking place at a very low level of conscious awareness. Our study captures the initial stages of this process. The similarity we see between UK-born and Polish-born adolescents' evaluative judgement patterns are most apparent on the solidarity dimension. As we are dealing with adolescent judges in this study, the fact that we are witnessing the acquisition of sociolinguistic awareness among the solidarity traits is perhaps to be expected. We might suppose that traits like 'interesting', 'friendly' and 'cool' are more socially salient to adolescents than e.g. 'rich' or 'intelligent'.

Notice, however, that the list of significant results in the ANOVAs presented in tables 3 and 4 is rather small i.e. there were many more similarities in the evaluation of these traits than there were differences. Among the Edinburgh data, only $9 \%$ of all evaluations were significantly different between the two groups of judges and in the London data, only $11 \%$ were. Does this mean that Polish-born adolescents have already acquired the social stereotypes found among their adolescent peer group for London English, Manchester English, Edinburgh English, Newcastle English and Scottish Standard English? Probably not. Recall from figures 2a and 3a 
that, among the UK-born data, only evaluations of RP and Birmingham English differ clearly from the middle of the range; the other six guises pattern more or less similarly and sit around the mid-range in the scale. Neither the UK-born nor Polishborn adolescents show strong reactions to most of the guises that they were presented with. It is therefore very difficult to ascertain whether the similarity in these results is evidence of the acquisition of sociolinguistics awareness among Polish-born adolescents or simply evidence of indifference among both UK-born and Polish-born judges. Our suspicion is the latter and we suggest that this is perhaps an artefact of using adolescent judges in our study. Some evidence in support of this suggestion comes from a real-time investigation of attitude change through the lift-span. El-Dash \& Busnardo (2001) report on a study which compares the attitudes of Brazilians towards English in 1991, when the individuals in their study were adolescents, and then again in 2001, when the individuals were young adults. In the initial study, the adolescents were found to regard English guises higher in terms of solidarity whereas the Portuguese guises were regarded higher in terms of status/power. However, by the time that these individuals were re-sampled ten years later, they had experienced a shift in attitudes and, in 2001, they regarded the English guises higher in status/power and the Portuguese higher in terms of solidarity. That is, they had changed their attitudes and now approximated the general trend found among the adult population in Brazil. El-Dash and Busnardo (2001) suggest that the patterns displayed by adolescents in their study "can be interpreted as revealing a general lack of experience with the prestige of English in the adult world" (2001:71). We suggest that the largely similar evaluation strategies we see among the UK-born and Polish-born adolescents here is less likely to be evidence of the acquisition of sociolinguistic awareness among Polish-born adolescents living in the UK and more likely to be 
evidence of a tendency among all adolescents to avoid extreme characterisations, perhaps as a result of their stage of maturational development.

\section{Conclusion}

This study set out to investigate the acquisition of sociolinguistic awareness among Polish-born adolescents living in the UK. Having dealt with the acquisition of sociolinguistic knowledge in production in (Schleef et al, under review), this paper addressed the acquisition of the perception-end of sociolinguistic knowledge. Specifically, it considered whether (a) Polish adolescent immigrants could accurately identify different varieties of English and (b) Polish adolescent immigrants were adopting the same evaluative judgements towards varieties of English as their locallyborn peer group. In response to (a), the results of a variety recognition survey suggested that Polish-born adolescents living in the UK are not yet able to identify different varieties of English. We hypothesised that this would have a knock-on effect to (b) and that Polish-born adolescents would evaluate varieties of English differently than UK-born adolescents. This is not the case: the vast majority of evaluations carried out by Polish-born adolescents and UK-born adolescents were not statistically different. However, as these similar results also cluster around the middle of the range in both data sets, we suspect that this is less likely to be evidence of the acquisition of sociolinguistic awareness among Polish immigrants learning English and more likely to be an artefact of the life-stage of our judges. However, we do see evidence of the acquisition of the muted evaluations that are typically associated with the two varieties of English that are most positively and negatively evaluated among the UK-born adolescents: RP and Birmingham English. The evaluative judgements carried out by Polish-born adolescents on Birmingham English provide the clearest evidence of the acquisition of sociolinguistic competence. Polish-born adolescents 
learning English in the UK evaluate Birmingham English lower than any other variety of English (although their negative evaluations are not yet as extreme as the negative evaluations found among UK-born adolescents). The similarity we see between UKborn and Polish-born adolescents' evaluative judgement patterns are most apparent on the solidarity dimension and we propose that this is because 'solidarity' traits are more socially salient among adolescents than 'status' traits.

One limitation to our study is the relatively low number of informants (compared with other more recent attitude studies which employ data collected from hundreds of respondents, e.g. McKenzie 2010). This is unfortunate because it means that the empirical analyses we present should be viewed as highlighting tendencies rather than absolute linguistic facts but, even so, we suggest that our study may still provide a snap-shot of the initial stages of the acquisition of attitudes towards variation in a second language.

Acknowledgements

This research was funded by the ESRC (RES-000-22-3244) and conducted in collaboration with Miriam Meyerhoff. We are extremely grateful to Robert McKenzie and Remco Knooihuizen for providing extensive comments on an earlier draft of this article, and to the audience of the $40^{\text {th }}$ Poznan Linguistics Meeting and the English Language Research Group at Edinburgh University where parts of this work was presented. Thanks also go to Satori Soden who collected data in London. The high schools we worked in remain anonymous, but we owe a debt of great magnitude to the staff and students in Edinburgh and London who worked with us on this project. In particular, our thanks go to the migrant teenagers, for some of whom the interview and reading tasks were a major effort. We admire and respect the individuals in these schools for the work they are doing. We alone are responsible for any failings in this paper. 
Table 1: measuring correct identification of guises

\begin{tabular}{l|lll}
\hline Guise example & response & level of identification & points awarded \\
\hline Polish English & Africa & Incorrect country & 0 \\
& Poland & Correct country & 1 \\
\hline \multirow{2}{*}{ Scottish Standard English } & America & Incorrect country & 0 \\
& UK & Correct country & 1 \\
& Scotland & Correct region & 2 \\
\hline Newcastle English & Russia & Incorrect country & 0 \\
& UK & Correct country & 1 \\
& England & Correct region & 2 \\
& Newcastle & Correct city & 3 \\
\hline
\end{tabular}


Table 2: mean identification results for all eight guises among four speaker groups (average over 6560 responses).

\begin{tabular}{l|llllc}
\hline & $\begin{array}{l}\text { Edinburgh } \\
\text { natives }\end{array}$ & $\begin{array}{l}\text { Edinburgh } \\
\text { Poles }\end{array}$ & $\begin{array}{l}\text { London } \\
\text { natives }\end{array}$ & $\begin{array}{l}\text { London } \\
\text { Poles }\end{array}$ & Scale \\
\hline Polish English & 0.71 & 0.94 & 0.58 & 0.95 & $0-1$ \\
SSE & 1.43 & 0.63 & 1.17 & 0.10 & $0-2$ \\
RP & 1.76 & 0.63 & 1.96 & 0.86 & \\
& & & & & \\
Edinburgh & 2.57 & 1.44 & 1.83 & 1.26 & $0-3$ \\
London & 1.29 & 1.06 & 2.25 & 1.10 & \\
Birmingham & 1.24 & 0.50 & 1.58 & 0.43 & \\
Manchester & 1.33 & 0.75 & 1.79 & 0.38 & \\
Newcastle & 1.64 & 0.66 & 0.99 & 1.06 & \\
\hline
\end{tabular}


Table 3: ANOVA of verbal-guise data comparing Edinburgh-born adolescents (Scottish in table 3) with and Edinburgh-based Poles (Polish in table 3); mean evaluations of individual traits and eight guises. Only significant differences in mean evaluations of specific traits reported here.

\begin{tabular}{|c|c|c|c|c|c|c|c|c|c|}
\hline & & $N$ & Mean & Std. Error & Std. Dev & Min & $\operatorname{Max}$ & $F$ Value & Sig. \\
\hline \multirow{3}{*}{$\begin{array}{l}\text { RP } \\
\text { educated }\end{array}$} & Polish & 16 & 64.9 & 5.5 & 21.86 & 16 & 94 & & \\
\hline & Scottish & 21 & 84.1 & 3.1 & 14.13 & 56 & 100 & & \\
\hline & Total & 37 & 75.8 & 3.3 & 20.07 & 16 & 100 & 10.448 & 0.003 \\
\hline \multirow{3}{*}{$\begin{array}{l}\mathrm{RP} \\
\text { intelligent }\end{array}$} & Polish & 16 & 50.6 & 7.2 & 28.66 & 2 & 100 & & \\
\hline & Scottish & 21 & 75.5 & 4.1 & 18.78 & 18 & 100 & & \\
\hline & Total & 37 & 64.7 & 4.3 & 26.35 & 2 & 100 & 10.127 & 0.003 \\
\hline \multirow{3}{*}{$\begin{array}{l}\mathrm{RP} \\
\text { rich }\end{array}$} & Polish & 16 & 44.3 & 4.8 & 19.36 & 6 & 76 & & \\
\hline & Scottish & 20 & 70.0 & 5.3 & 26.49 & 13 & 99 & & \\
\hline & Total & 36 & 58.5 & 4.2 & 24.33 & 6 & 99 & 12.392 & 0.001 \\
\hline \multirow{3}{*}{$\begin{array}{l}\mathrm{RP} \\
\text { posh }\end{array}$} & Polish & 16 & 45.4 & 6.5 & 25.88 & 8 & 98 & & \\
\hline & Scottish & 21 & 78.6 & 4.5 & 20.80 & 21 & 100 & & \\
\hline & Total & 37 & 64.3 & 4.6 & 28.24 & 8 & 100 & 18.711 & 0.000 \\
\hline \multirow{3}{*}{$\begin{array}{l}\text { Birmingham } \\
\text { interesting }\end{array}$} & Polish & 16 & 32.4 & 8.4 & 33.66 & 3 & 96 & & \\
\hline & Scottish & 21 & 12.5 & 3.0 & 13.83 & 1 & 50 & & \\
\hline & Total & 37 & 21.1 & 4.3 & 26.04 & 1 & 96 & 6.015 & 0.019 \\
\hline \multirow{3}{*}{$\begin{array}{l}\text { Birmingham } \\
\text { educated }\end{array}$} & Polish & 16 & 73.0 & 4.4 & 17.59 & 43 & 97 & & \\
\hline & Scottish & 21 & 47.6 & 7.1 & 32.56 & 1 & 99 & & \\
\hline & Total & 37 & 58.6 & 4.9 & 26.67 & 1 & 99 & 7.919 & 0.008 \\
\hline \multirow{3}{*}{$\begin{array}{l}\text { SSE } \\
\text { reliable }\end{array}$} & Polish & 16 & 57.4 & 6.1 & 24.29 & 4 & 97 & & \\
\hline & Scottish & 21 & 75.1 & 3.4 & 15.36 & 49 & 99 & & \\
\hline & Total & 37 & 67.4 & 3.5 & 21.36 & 4 & 99 & 7.351 & 0.010 \\
\hline
\end{tabular}


Table 4: ANOVA of verbal-guise data comparing London-born adolescents (English in table 4) with London-based Poles (Polish in table 4), mean evaluations of individual traits on eight guises. Only significant differences in mean evaluations of specific traits reported here.

\begin{tabular}{|c|c|c|c|c|c|c|c|c|c|}
\hline & & $N$ & Mean & Std. Error & Std.Dev & Min. & Max. & $F$ Value & Sig. \\
\hline \multirow{3}{*}{$\begin{array}{l}\text { RP } \\
\text { intelligent }\end{array}$} & English & 24 & 80.33 & 2.73 & 13.38 & 42 & 98 & & \\
\hline & Polish & 21 & 60.71 & 4.13 & 18.94 & 31 & 98 & & \\
\hline & Total & 45 & 71.18 & 2.81 & 18.83 & 31 & 98 & 16.402 & 0.000 \\
\hline \multirow{3}{*}{$\begin{array}{l}\mathrm{RP} \\
\text { rich }\end{array}$} & English & 24 & 74.33 & 3.33 & 16.31 & 39 & 99 & & \\
\hline & Polish & 21 & 52.10 & 4.76 & 21.79 & 2 & 82 & & \\
\hline & Total & 45 & 63.96 & 3.27 & 21.22 & 2 & 99 & 15.246 & 0.000 \\
\hline \multirow{3}{*}{$\begin{array}{l}\text { RP } \\
\text { posh }\end{array}$} & English & 24 & 77.17 & 3.24 & 15.89 & 35 & 100 & & \\
\hline & Polish & 21 & 42.86 & 4.47 & 20.47 & 8 & 74 & & \\
\hline & Total & 45 & 61.16 & 3.72 & 24.92 & 8 & 100 & 39.952 & 0.000 \\
\hline \multirow{3}{*}{$\begin{array}{l}\text { Birmingham } \\
\text { reliable }\end{array}$} & English & 23 & 50.00 & 4.64 & 22.23 & 10 & 98 & & \\
\hline & Polish & 21 & 64.62 & 3.25 & 14.88 & 42 & 98 & & \\
\hline & Total & 44 & 56.98 & 3.05 & 20.26 & 10 & 98 & 6.438 & 0.015 \\
\hline \multirow[t]{3}{*}{ Birmingham posh } & English & 24 & 34.79 & 3.21 & 15.74 & 3 & 65 & & \\
\hline & Polish & 21 & 49.67 & 4.57 & 20.93 & 21 & 88 & & \\
\hline & Total & 45 & 41.73 & 2.93 & 19.62 & 3 & 88 & 7.364 & 0.01 \\
\hline \multirow{3}{*}{$\begin{array}{l}\text { Edinburgh } \\
\text { interesting }\end{array}$} & English & 23 & 55.13 & 4.79 & 22.98 & 17 & 88 & & \\
\hline & Polish & 21 & 35.95 & 4.59 & 21.05 & 9 & 87 & & \\
\hline & Total & 44 & 45.98 & 3.60 & 23.88 & 9 & 88 & 8.278 & 0.006 \\
\hline \multirow{3}{*}{$\begin{array}{l}\text { Edinburgh } \\
\text { friendly }\end{array}$} & English & 23 & 68.96 & 4.37 & 20.98 & 12 & 98 & & \\
\hline & Polish & 19 & 48.95 & 5.71 & 24.87 & 4 & 90 & & \\
\hline & Total & 42 & 59.90 & 3.81 & 24.68 & 4 & 98 & 8.001 & 0.007 \\
\hline \multirow{3}{*}{$\begin{array}{l}\text { Edinburgh } \\
\text { intelligent }\end{array}$} & English & 24 & 66.38 & 2.93 & 14.37 & 40 & 87 & & \\
\hline & Polish & 21 & 55.00 & 4.81 & 22.04 & 4 & 95 & & \\
\hline & Total & 45 & 61.07 & 2.84 & 19.02 & 4 & 95 & 4.306 & 0.044 \\
\hline \multirow{3}{*}{$\begin{array}{l}\text { London } \\
\text { posh }\end{array}$} & English & 24 & 25.83 & 3.86 & 18.91 & 1 & 77 & & \\
\hline & Polish & 21 & 42.90 & 5.24 & 23.99 & 1 & 86 & & \\
\hline & Total & 45 & 33.80 & 3.41 & 22.86 & 1 & 86 & 7.11 & 0.011 \\
\hline
\end{tabular}


Figure 1: instructions to participants and semantic differential scale

Instructions

You will hear 8 people reading from a newspaper. Listen to each person and put a cross on the line where you would put each person on the scale:

For example: If you thought the first person on the tape was pretty boring in real life, you might put a cross somewhere near "boring"

boring ---------Xinteresting

There is no 'right' answer - this is NOT a test!

$\underline{\text { Speaker } 1}$

boring interesting

educated

unfriendly

unintelligent

pleasant uneducated

trustworthy

not cool

intelligent

poor unpleasant trustworthy

reliable

common 
Figure 2: overall mean evaluations of eight guises across speaker groups (6560 responses)

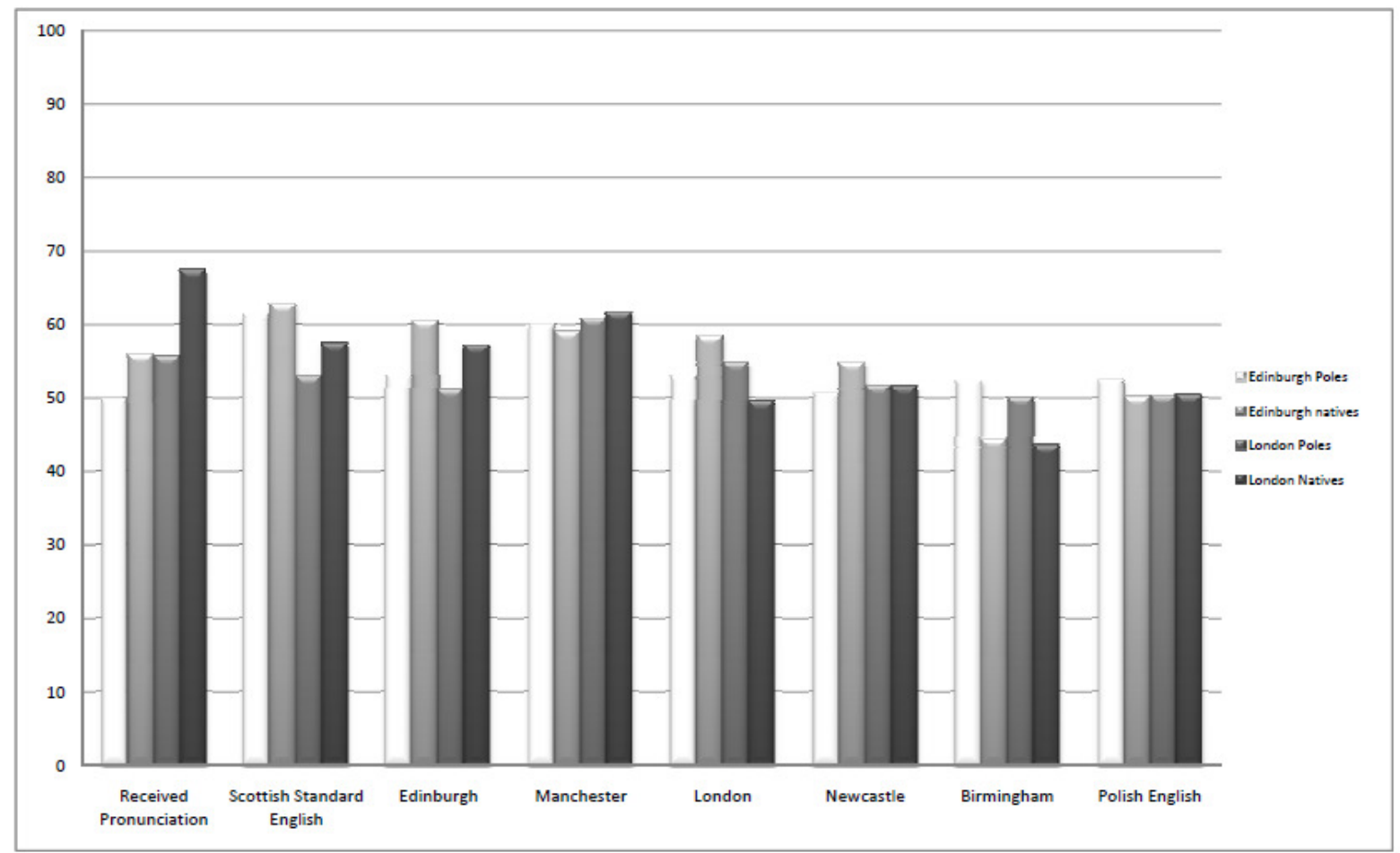


Figure 3a: Evaluative judgements of eight guises across ten personality traits by Edinburgh-born adolescents (1680 responses).

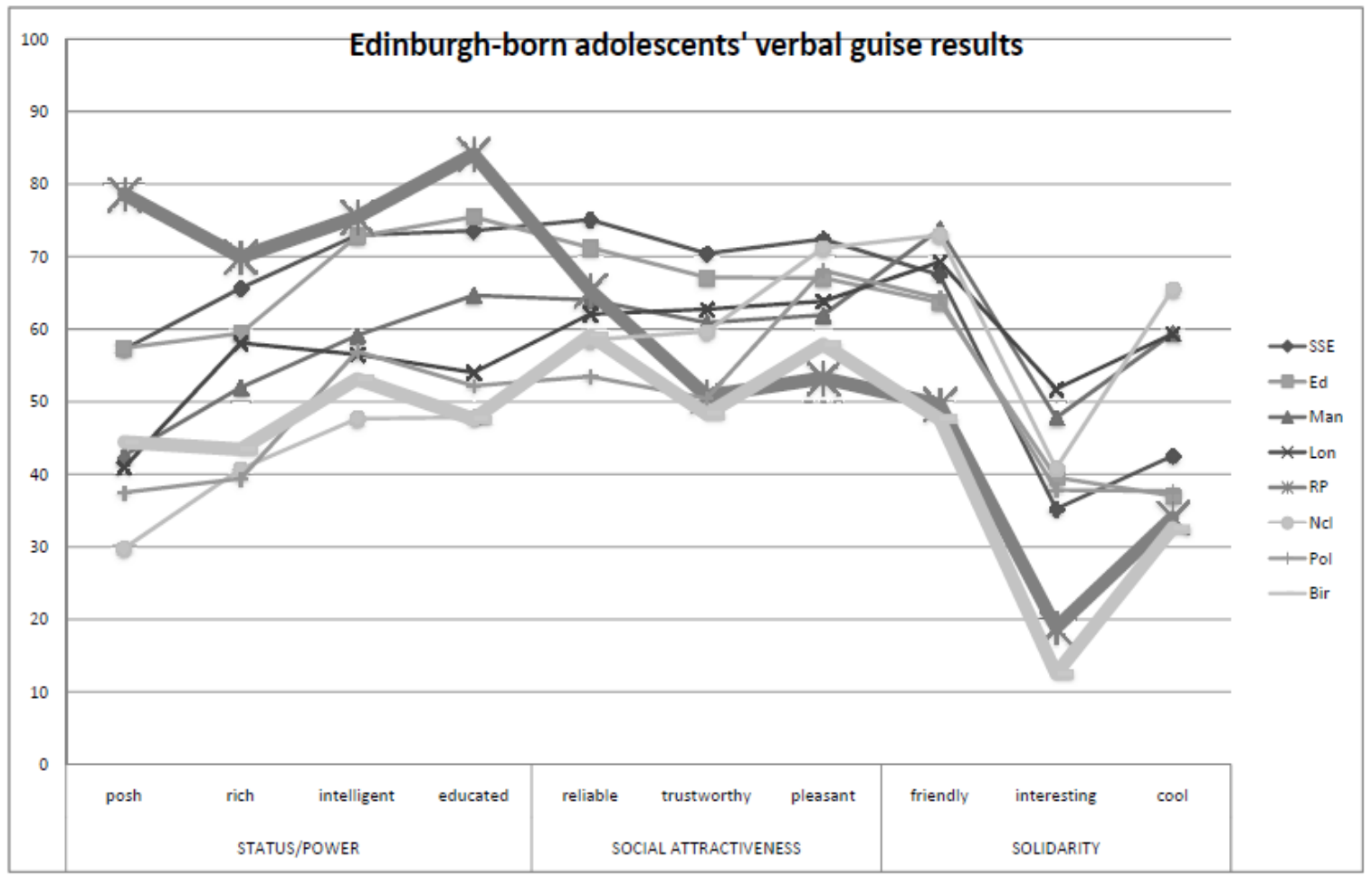


Figure 3b: Evaluative judgements of eight guises across ten personality traits by London-born adolescents (1920 responses).

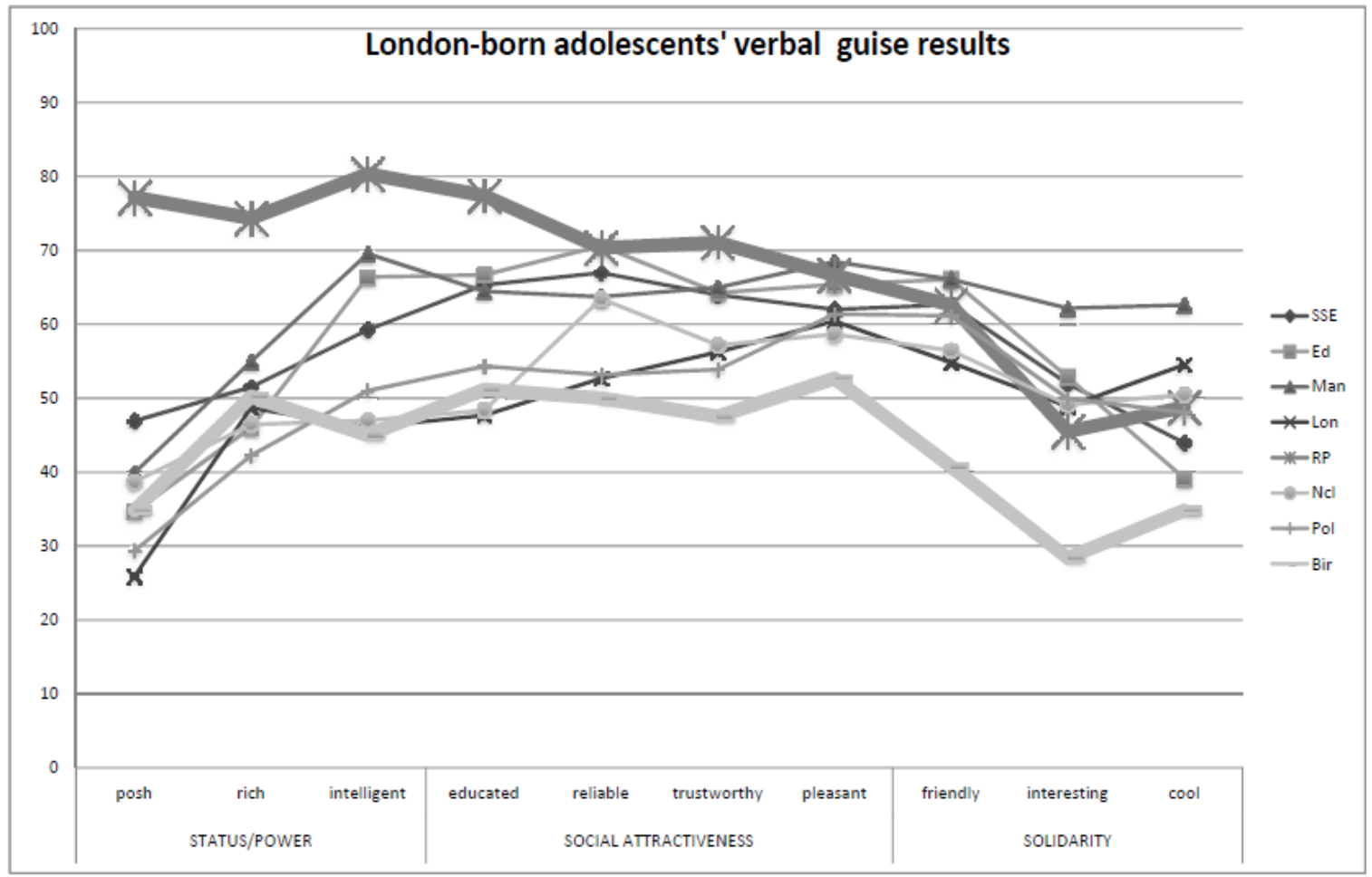


Figure 4a: Evaluative judgements of eight guises across ten personality traits by Polish-born adolescents living in Edinburgh (1280 responses).

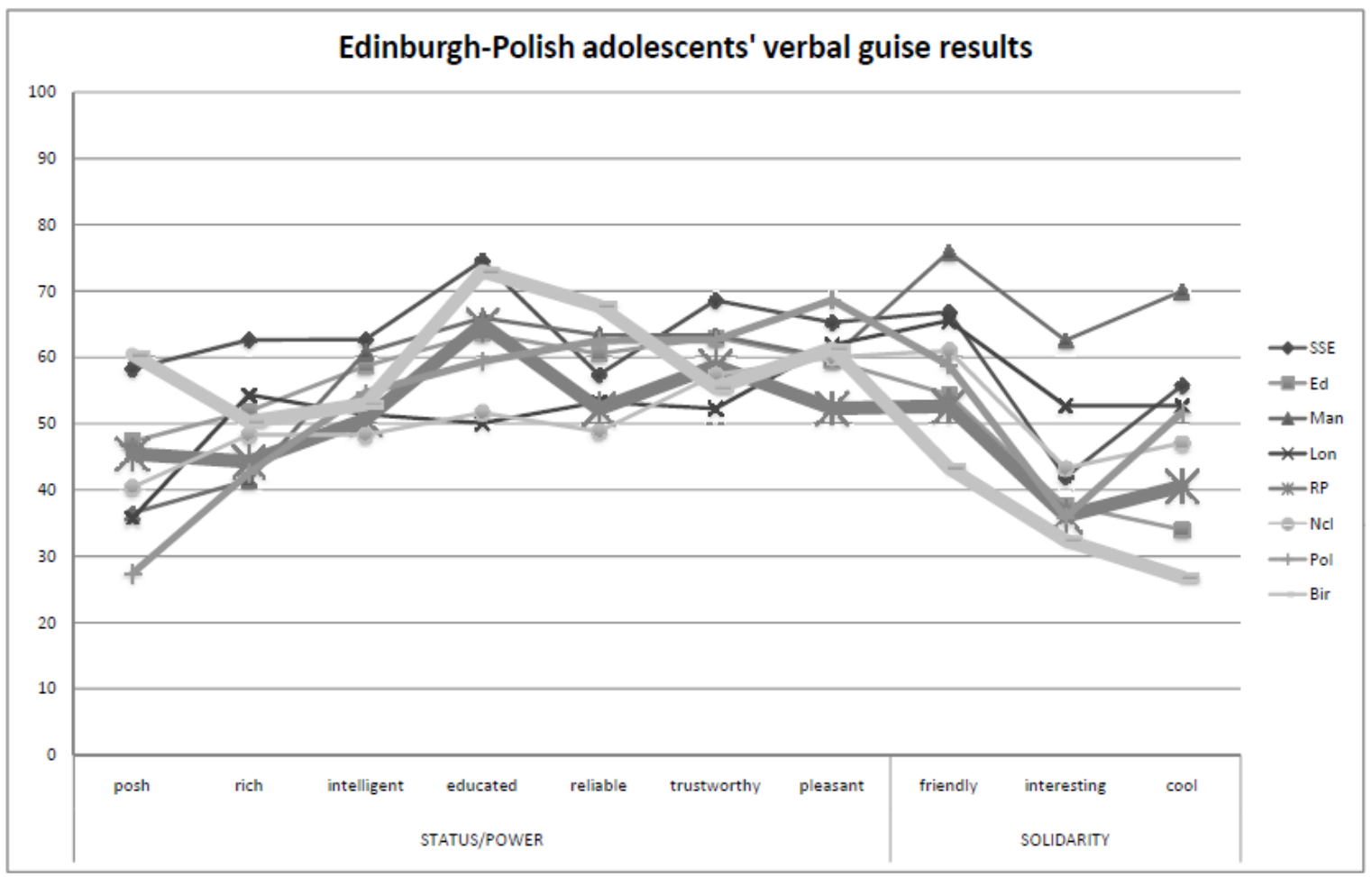


Figure 4b: Evaluative judgements of eight guises across ten personality traits by Polish-born adolescents living in London (1680 responses).

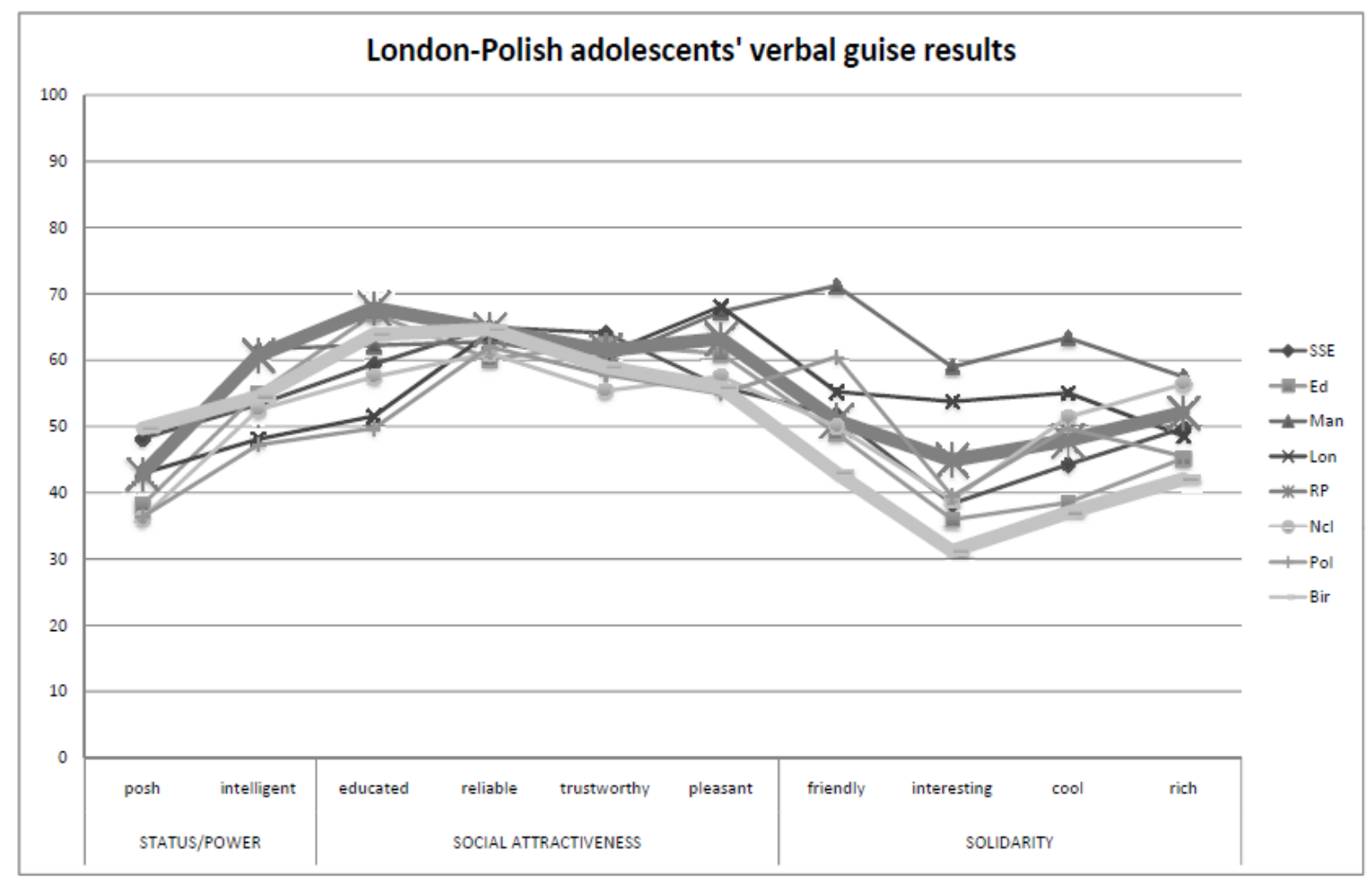


Footnotes

1. The Workers Registration Scheme (WRS) can be used as a measure of the number of migrant citizens coming to work in the UK but it provides no indication of their length of stay and, because the WRS exclude the self employed, it is likely that these figures hugely underestimate the actual number of migrant workers in the UK.

2. Following Poplack \& Tagliamonte (2001:93), our approach assumes that the constraints operating on linguistic variation (uncovered in an analysis of variation using multiple regression) represent the variable grammar of the speech community and so differences in the constraints and ranking of constraints among UK-born adolescents and Polish-born adolescents living in the UK can be interpreted as "diagnostics of fundamentally different underlying grammars" (Meyerhoff 2009:303).

3. The Verbal Guise Test (VGT) is a variant of the Matched Guise Test (MGT) which was originally developed by Lambert et al (1960). The main difference between these two methods of data collection is that a number of different speakers (with different linguistic characteristics) provide the stimulus for a VGT whereas with a MGT, the same speaker produces a number of different linguistic 'guises'.

4. Redinger and Llamas (2009) discuss in detail the advantages of employing magnitude estimation techniques in attitude research in detail.

5. Thanks to one of the reviewers of this article for suggesting this point.

6. Eigen values are a measure of the amount of variance accounted for by each of the components extracted in PCA. The Keiser Criterion is the most commonly used method of establishing which components are relevant in PCA. The rule of thumb is that factors should be extracted with eigenvalues greater or equal to 1 (i.e. $10 \%$ of the variance). Components with an eigenvalue smaller than this are not contributing more to the model than a single variable and so are meaningless.

7. One reviewer questioned the use of ANOVA rather than a simple t-tests. While it would have been possible to analyse these data using multiple t-tests, this increases the probability of committing at least one Type 1 Error. The ANOVA procedure performs fewer hypothesis tests and so reduce the likelihood of experiment-wise error. 
References

Al-Hindawe, J. (1996) "Considerations when constructing a semantic differential scale". La Trobe Papers in Linguistics, 9(7).

Bauere, V., Densham, P., Millar, J., \& Salt, J. (2007) "Migrants from Central and Eastern Europe: local geographies". Population Trends, 129: 7-19.

Bard, E.G., Robertson, D., Sorace, A. (1996) "Magnitude Estimation of Linguistic Acceptability". Language 72: 32-68.

Bishop, H., Coupland, N. \& P. Garrett (2005) "Conceptual accent evaluation: Thirty years of accent prejudice in the U.K". Acta Linguistica Havniensia 37: 131154.

Coupland, N. \& H. Bishop (2007) "Ideologised values for British accents". Journal of Sociolinguistics 11(1): 74-93.

Dalton-Puffer, C., Kaltenboeck, G \& U. Smit. (1997) "Learner attitudes and L2 pronunciation in Austria". World Englishes, 16(1): 115-128.

Dörnyei, Z. (2003). "Attitudes, orientations, and motivations in language learning: Advances in theory, research, and applications". In: Dornyei, Z. (ed.) Attitudes, orientations, and motivations in language learning. Oxford: Blackwell, 3-32.

Dörnyei, Z.\& P. Skehan (2003) "Individual differences in second language learning". In Doughty, C, J. M. H Long. (eds.) The Handbook of Second Language Acquisition. Oxford: Blackwell, 589-630.

Edwards, J. (1982) "Language attitudes and their implications among English speakers". In Ryan, E.B \& H. Giles (eds.) Attitudes Towards Language Variation: Social and Applied Contexts. London: Edward Arnold, 20-33.

Eisenstein, M. (1982) "A study of social variation in adult second language acquisition". Language Learning 32: 367-391.

El-Dash, L. and J. Busnardo (2001) "Brazilian attitudes towards English: dimensions of status and solidarity". International Journal of Applied Linguistics. 11 (1): $57-74$.

Ellis, R. (1994). The Study of Second Language Acquisition. Oxford: Oxford University Press.

Gardner, R. C. (1985). Social psychology and second language learning: The role of attitudes and motivation. London: Edward Arnold.

Giles, H. (1970). "Evaluative reactions to accents". EducationalReview 22: 211-227.

Giles, H., \& Powesland, P. F. (1975). Speech evaluation and social evaluation. London: Academic Press.

Giles, H. \& N. Coupland (1991) Language: Context and Consequences. Oxford: Oxford University Press.

Jarvella, R., E. Bang, A.L. Jakobsen, I.M. Mees (2001) "Of mouths and men: nonnative listeners' identification and evaluation of varieties of English". International Journal of Applied Linguistics 11 (1): 37-56.

Kristiansen, T \& M. Monka (2006) "Language ideology in Danish adolescents: two value systems at two levels of consciousness. Design of the LANCHART studies of language attitudes - with results from Odder". Report available at http://lanchart.hum.ku.dk/reports/

Ladegaard, H. (1998) "National stereotypes and language attitudes: the perception of British, American and Australian language and culture in Denmark. Language and Communication, 18, 251-274.

Labov, W. (1969) "Contraction, deletion, and inherent variability of the English Copula", Language 45 (4): 715-762. 
Labov, W.(1972). Sociolinguistic Patterns. Philadelphia: University of Pennsylvania Press.

Labov, W. (2001). Principles of language change: social factors. Malden, Massachusetts: Blackwell.

Lambert, W., R. Hodgson, R. Gardner and S. Fillenbaum (1960) Evaluational reactions to spoken languages. Journal of Abnormal and Social Psychology, 60, 44-51.

McKenzie, R. (2008a) "Social factors and non-native attitudes towards varieties of spoken English: a Japanese case study". International Journal of Applied Linguistics 18(1): 63-88.

McKenzie, R (2008b) "The Role of Variety Recognition in Japanese University Students' Attitudes Towards English Speech Varieties". Journal of Multilingual and Multicultural Development. 29(2): 139-153

McKenzie, R (2010) The Social Psychology of English as a Global Language. Dordrecht: Springer.

Meyerhoff, M. (2003). "Formal and cultural constraints on optional objects in Bislama". Language Variation and Change 14(3):323-346.

Meyerhoff, M. (2009) "Replication, transfer, and calquing: Using variation as a tool in the study of language contact". Language Variation and Change 21: 297317

Reynolds, G (2008) "The impacts and experiences of migrant children in UK secondary schools". Sussex working papers in migration research, 47: 1-34.

Redinger, D., Llamas, C. (2009) 'Innovations in the measurement and analysis of language attitudes'. Poster presented at Production Perception Attitude, Leuven, Belgium, April 2009.

Poplack, S. \& S. Tagliamonte (2001). African American English in the diaspora. Oxford: Blackwell.

Salt, J., Miller, J. (2006). "Foreign labour in the United Kingdom: current patterns and trends". In Office of National Statistics: labour market trends (Ed.) (pp. 335$355)$.

Schleef, E., Clark,L.,Meyerhoff, M (under review) “Teenagers' acquisition of variation: A comparison of locally-born and migrant teens' realisation of English (ing) in Edinburgh and London". Under review with English World Wide.

Tucker, G. R. and W. E. Lambert. (1969). "White and Negro Listeners' Reactions to Various American English Dialects." Social Forces. 47:463-468.

Williams, A., P. Garrett, \& N. Coupland. (1999) “Dialect recognition”. In D.R. Preston (ed.) Handbook of Perceptual Dialectology (Vol. 1, pp. 345_358). Amsterdam: John Benjamins. 